\title{
Characteristics and prediction of subclinical hypocalcemia in dairy cows during the transition period using blood analytes*
}

\author{
XINRU MA ${ }^{1 * *}$, CHANGHONG GAO ${ }^{1 * *}$, MINGMAO YANG ${ }^{1}$, \\ BINGBING ZHANG ${ }^{2}$, XU CHUANG ${ }^{1}$, WEI YANG ${ }^{1}$
}

\author{
${ }^{1}$ College of Animal Science and Veterinary Medicine, ${ }^{2}$ College of Life Science and Technology, \\ Heilongjiang Bayi Agricultural University, Daqing 163319, China \\ ** Xinru Ma and Changhong Gao contributed equally to this work
}

Ma X., Gao Ch., Yang M., Zhang B., Chuang X., Yang W.

Characteristics and prediction of subclinical hypocalcemia in dairy cows during the transition period using blood analytes

\section{Summary}

This study aimed to present the characteristics of and to predict subclinical hypocalcemia in dairy cows during the transition period using blood analytes. We examined fluctuations in plasma calcium (Ca), phosphorus (P), bone metabolic markers carboxy-terminal telopeptide of type I collagen (CTX), fibroblast growth factor (FGF23), 1,25(OH) $)_{2}$, parathyroid hormone, and other blood biochemical analytes from prepartum week 2 to postpartum day 14 in 116 multiparous high-producing Holstein cows from a free-stall barn dairy farm. With a plasma concentration of $\mathrm{Ca}<\mathbf{2 . 0} \mathbf{~ m m o l} / \mathrm{L}$ as a criterion for the diagnosis of subclinical hypocalcemia, 64 cows were classified as normocalcemic, and 52 cows as subclinically hypocalcemic. Among the 52 hypocalcemic cows, 50 were detected on postpartum days 1 or 3 , and 2 on postpartum day. The subclinically hypocalcemic cows were in a state of low bone turnover in the prepartum period, with low plasma concentrations of $\mathrm{Ca}$ and CTX. The subclinically hypocalcemic cows showed signs of a $P$ regulation disorder in the prepartum period. This was marked by high plasma concentrations of $P$ and low concentrations of $1,25(\mathrm{OH})_{2} D_{3}$ and FGF23, which is also considered to be the cause of the low bone turnover. The results of a multiple logistic regression model showed that prepartum plasma concentrations of FGF23, CTX, and Ca were ideal predictors of postpartum subclinical hypocalcemia in dairy cows, using the model equation $38.8-0.052 * \mathrm{FGF} 23-0.492 * \mathrm{CTX}-10.645 * \mathrm{Ca}$, with a score of $>0$ considered as an indication of increased risk of subclinical hypocalcemia after calving. The scoring rule had an accuracy of $79.3 \%$, sensitivity of $76.9 \%$, and specificity of $81.3 \%$. The plasma concentrations of FGF23, CTX, and Ca were ideal predictors of postpartum subclinical hypocalcemia in dairy cows.

Keywords: dairy cow, subclinical hypocalcemia, blood analytes, FGF23, CTX

Hypocalcemia is a common metabolic disorder in which homeostatic mechanisms fail to maintain normal blood calcium (Ca) concentrations at the onset of lactation (1). As many as $50 \%$ of periparturient dairy cows may have subclinical hypocalcemia, which was defined in a prospective cohort study as blood $\mathrm{Ca}$ of $1.38-2.0 \mathrm{mmol} / \mathrm{L}$ on post-calving days 1 to 2 with no clinical symptoms $(14,20)$. Cows with hypocalcemia are at an increased risk of developing other periparturi-

* This work was supported by Heilongjiang Province General Undergraduate Colleges and Universities Young Innovative Talents Training Program (UNPYSCT-2018081), and China Agriculture Research System (CARS-36) and The central government supports local colleges and universities reform and development funds. ent problems, including displaced abomasum, ketosis (19), fatty liver, retained placenta, metritis, and mastitis (10). Furthermore, hypocalcemic cows have a reduced proportion of neutrophils with phagocytic activity (9) and an impaired mononuclear cell response to an antigen-activating stimulus (6). At the onset of lactation, the synthesis and secretion of colostrum leads to major losses of $\mathrm{Ca}$, which are equivalent to 7-10 times the amount of $\mathrm{Ca}$ in blood $(4,10)$. To cope with this rapid loss of $\mathrm{Ca}, \mathrm{Ca}$ resorption from bone is increased. The plasma concentration of carboxy-terminal telopeptide of type I collagen (CTX) is commonly used as a marker of bone resorption. Bone Ca mobilization is regulated by parathyroid hormone $(\mathrm{PTH})$, which is activated by 
lower Ca concentrations to increase $1,25(\mathrm{OH})_{2} \mathrm{D}_{3}$ synthesis, improve urinary $\mathrm{Ca}$ reabsorption, and stimulate the intestine to efficiently absorb dietary $\mathrm{Ca}$ (3). In addition, fibroblast growth factor 23 (FGF23) is secreted by osteocytes in response to elevated $1,25(\mathrm{OH})_{2} \mathrm{D}_{3}$ and is responsible for phosphorus $(\mathrm{P})$ and $1,25(\mathrm{OH})_{2} \mathrm{D}_{3}$ metabolism and subsequent impairment of $\mathrm{Ca}$ absorption (13). The aim of the present study is to present the characteristics of $\mathrm{Ca}$ homeostasis from late pregnancy to early lactation in dairy cows, to identify potential regulators of hypocalcemia, and to explore biomarkers predictive of subclinical hypocalcemia during the transition period.

\section{Material and methods}

Animal grouping and sampling. The study protocol was approved by the Ethics Committee for the Use and Care of Animals, Heilongjiang Bayi Agricultural University (Daqing, China). The study cohort included 116 multiparous high-producing Holstein cows (with a mean of postpartum $3.10 \pm 0.72$ parities and a mean body condition score of $3.51 \pm 0.06$ ) from a free-stall barn dairy farm, which were fed a total mixed ration (TMR) (Tab. 1) during the transition period. Plasma total $\mathrm{Ca}$ was used as a diagnostic marker of subclinical hypocalcemia, which was defined as a postpartum serum $\mathrm{Ca}$ concentration of $<2.0 \mathrm{mmol} / \mathrm{L}$

Tab. 1. Components and nutrient levels in the feeds

\begin{tabular}{|c|c|}
\hline Item & Diet \\
\hline \multicolumn{2}{|l|}{ Ingredient, g/kg } \\
\hline Corn silage & 380.32 \\
\hline Alfalfa & 50.71 \\
\hline Oat grass & 25.35 \\
\hline Chinese hay & 22.82 \\
\hline Cotton seed & 32.96 \\
\hline Soybean & 21.30 \\
\hline Tableting corn & 32.45 \\
\hline Concentrated feed & 234.53 \\
\hline Water & 199.34 \\
\hline DM (\%) & 58.26 \\
\hline \multicolumn{2}{|l|}{ Composition,\% DM } \\
\hline NDF & 39.08 \\
\hline ADF & 21.05 \\
\hline Starch & 15.36 \\
\hline Crude protein & 16.25 \\
\hline Crude fat & 6.09 \\
\hline Gross energy (Mcal/kg) & 2.54 \\
\hline Total carbon & 43.45 \\
\hline $\mathrm{Ca}$ & 1.06 \\
\hline $\mathrm{p}$ & 0.45 \\
\hline
\end{tabular}

Explanations: DM - dry matter; NDF - neutral detergent fiber; ADF - acid detergent fiber measured with an enzyme-linked immunosorbent kit (Westang Biotechnology Co., Ltd., Shanghai, China).

Statistical analysis. Plasma biochemical analytes are presented as mean \pm SD. Differences between the subclinical hypocalcemia and normocalcemia groups were identified by repeated measures analysis of variance. $\mathrm{P}<0.05$ was considered statistically significant. To predict subclinical hypocalcemia, data for each plasma biochemical analyte 1 and 2 weeks prepartum were pooled. Each potential prepartum predictor was quantified using univariate logistic regression analysis with Wald's $\mathrm{P} \leq 0.25$ entered into a backwards stepwise multivariate regression model. The selected potential predictors, that is, FGF23, CTX, Ca, P, LDL-C, NEFA, $1,25(\mathrm{OH})_{2} \mathrm{D}_{3}, \mathrm{HDL}-\mathrm{C}$, and $\mathrm{Mg}$, were initially included in an overall "history model." A reduced "history model" was consecutively extended to evaluate the added value of each parameter for prediction of subclinical hypocalcemia, with $\mathrm{P} \leq 0.05$ considered significant. The capacity of each model to predict the occurrence of subclinical hypocalcemia was evaluated using the area under the receiver operating characteristic curve (ROC area) (5).

\section{Results and discussion}

Characteristics of blood analytes during the transition period. With plasma concentration of $\mathrm{Ca}$ $<2.0 \mathrm{mmol} / \mathrm{L}$ as the criterion for the diagnosis of subclinical hypocalcemia, 64 cows (with a mean of postpartum $3.06 \pm 0.77$ parities) were classified as normocalcemic, and 52 cows (with a mean of postpartum $3.15 \pm 0.69$ parities) as subclinically hypocalcemic. Among the 52 hypocalcemic cows, 50 were detected on postpartum days 1 or 3 , and 2 on postpartum day. Plasma Ca concentrations were significantly lower in the subclinically hypocalcemic cows than they were in the normocalcemic cows (Tab. 2) from prepartum week 2 to postpartum day 7 . Increase in bone $\mathrm{Ca}$ resorption and intestinal $\mathrm{Ca}$ absorption is a major homeostatic response to hypocalcemia (5). PTH is activated by lower $\mathrm{Ca}$ concentrations to increase $1,25(\mathrm{OH})_{2} \mathrm{D}_{3}$ synthesis and promote osteoclast formation, thereby increasing the amount of $\mathrm{Ca}$ mobilized from bone. There were no significant differences in the plasma concentration of PTH between the subclinical hypocalcemia and normocalcemia groups. Yamada et al. (17) report that serum biochemical markers of bone metabolism are believed to be more precise than the measurement of PTH because of interindividual variations in bone responsiveness to PTH. Intravenous treatment of subclinical hypocalcaemia has a positive effect without causing transient hypocalcemia (12). As a biochemical marker of bone resorption, plasma CTX was significantly higher in the normocalcemia group than in the subclinical hypocalcemia group. These dynamic changes might indicate a state of high bone turnover during the perinatal period among cows in the normocalcemia group.

In this study, plasma $\mathrm{P}$ concentrations were significantly higher in the subclinically hypocalcemic cows
(HDL-C). Plasma FGF23, 1,25(OH)2D3, PTH, and CTX concentrations were 
Tab. 2. Characteristics of plasma biochemical analytes and milk yield in dairy cows during the transition period

\begin{tabular}{|c|c|c|c|c|c|c|c|}
\hline \multirow{2}{*}{ Characteristic } & \multirow{2}{*}{ Group } & \multicolumn{6}{|c|}{ Transition period } \\
\hline & & prepartum week 2 & prepartum week 1 & postpartum day 1 & postpartum day 3 & postpartum day 7 & postpartum day 14 \\
\hline \multirow{2}{*}{$\mathrm{Ca}(\mathrm{mmol} / \mathrm{L})$} & $\mathbf{N}$ & $2.38 \pm 0.09$ & $2.39 \pm 0.09$ & $2.24 \pm 0.18$ & $2.20 \pm 0.15$ & $2.25 \pm 0.16$ & $2.31 \pm 0.13$ \\
\hline & SH & $2.31 \pm 0.08^{*}$ & $2.32 \pm 0.08^{*}$ & $1.98 \pm 0.21^{* *}$ & $1.89 \pm 0.17^{* *}$ & $2.14 \pm 0.15$ & $2.21 \pm 0.17$ \\
\hline \multirow{2}{*}{$P(\mathrm{mmol} / \mathrm{L})$} & $\mathbf{N}$ & $2.15 \pm 0.12$ & $2.10 \pm 0.17$ & $1.55 \pm 0.41$ & $1.82 \pm 0.52$ & $1.56 \pm 0.34$ & $1.87 \pm 0.32$ \\
\hline & SH & $2.26 \pm 0.26$ & $2.30 \pm 0.24^{*}$ & $1.66 \pm 0.59$ & $1.68 \pm 0.59$ & $1.73 \pm 0.29$ & $1.81 \pm 0.31$ \\
\hline \multirow{2}{*}{$\mathrm{Mg}(\mathrm{mmol} / \mathrm{L})$} & N & $0.87 \pm 0.17$ & $0.84 \pm 0.20$ & $0.87 \pm 0.17$ & $0.85 \pm 0.19$ & $0.78 \pm 0.17$ & $0.89 \pm 0.24$ \\
\hline & SH & $0.95 \pm 0.15$ & $0.88 \pm 0.13$ & $0.96 \pm 0.19$ & $0.93 \pm 0.13$ & $0.78 \pm 0.20$ & $0.88 \pm 0.19$ \\
\hline \multirow{2}{*}{ K (mmol/L) } & $\mathbf{N}$ & $3.90 \pm 0.22$ & $3.98 \pm 0.24$ & $4.01 \pm 0.37$ & $4.06 \pm 0.32$ & $3.84 \pm 0.33$ & $3.99 \pm 0.33$ \\
\hline & SH & $3.93 \pm 0.19$ & $3.93 \pm 0.25$ & $3.98 \pm 0.26$ & $3.97 \pm 0.29$ & $3.83 \pm 0.38$ & $4.05 \pm 0.32$ \\
\hline \multirow{2}{*}{ AST (U/L) } & N & $79 \pm 22$ & $79 \pm 20$ & $88 \pm 21$ & $107 \pm 22$ & $113 \pm 33$ & $115 \pm 29$ \\
\hline & SH & $82 \pm 29$ & $82 \pm 26$ & $111 \pm 49$ & $139 \pm 55^{*}$ & $108 \pm 13$ & $118 \pm 40$ \\
\hline \multirow{2}{*}{ GLU (mmol/L) } & N & $3.69 \pm 0.36$ & $3.72 \pm 0.26$ & $5.39 \pm 2.55$ & $3.23 \pm 0.73$ & $3.24 \pm 1.08$ & $3.18 \pm 0.76$ \\
\hline & SH & $3.73 \pm 0.30$ & $3.60 \pm 0.37$ & $4.70 \pm 2.23$ & $3.45 \pm 0.64$ & $3.28 \pm 1.17$ & $3.14 \pm 0.91$ \\
\hline \multirow{2}{*}{ NEFA (mmol/L) } & $\mathbf{N}$ & $0.11 \pm 0.09$ & $0.19 \pm 0.12$ & $0.42 \pm 0.39$ & $0.63 \pm 0.45$ & $0.57 \pm 0.40$ & $0.55 \pm 0.39$ \\
\hline & SH & $0.19 \pm 0.13$ & $0.19 \pm 0.13$ & $0.44 \pm 0.31$ & $0.38 \pm 0.20$ & $0.54 \pm 0.27$ & $0.44 \pm 0.23$ \\
\hline \multirow{2}{*}{ BHBA (mmol/L) } & N & $0.59 \pm 0.21$ & $0.48 \pm 0.16$ & $0.43 \pm 0.15$ & $0.83 \pm 0.54$ & $1.38 \pm 1.13$ & $1.67 \pm 1.39$ \\
\hline & SH & $0.58 \pm 0.20$ & $0.57 \pm 0.24$ & $0.42 \pm 0.15$ & $0.83 \pm 0.38$ & $1.24 \pm 0.90$ & $1.15 \pm 1.12$ \\
\hline \multirow{2}{*}{ TC (mmol/L) } & N & $2.15 \pm 0.40$ & $1.92 \pm 0.45$ & $1.70 \pm 0.42$ & $1.79 \pm 0.33$ & $2.07 \pm 0.50$ & $2.73 \pm 0.75$ \\
\hline & SH & $2.03 \pm 0.34$ & $1.98 \pm 0.23$ & $1.56 \pm 0.29$ & $1.67 \pm 0.44$ & $1.76 \pm 0.56$ & $2.41 \pm 0.85$ \\
\hline \multirow{2}{*}{ TG (mmol/L) } & N & $0.30 \pm 0.05$ & $0.29 \pm 0.10$ & $0.16 \pm 0.05$ & $0.15 \pm 0.03$ & $0.16 \pm 0.03$ & $0.17 \pm 0.02$ \\
\hline & SH & $0.33 \pm 0.08$ & $0.28 \pm 0.07$ & $0.16 \pm 0.05$ & $0.13 \pm 0.02$ & $0.15 \pm 0.02$ & $0.18 \pm 0.04$ \\
\hline \multirow{2}{*}{ HDL-C (mmol/L) } & N & $1.28 \pm 0.14$ & $1.24 \pm 0.19$ & $1.17 \pm 0.22$ & $1.24 \pm 0.26$ & $1.46 \pm 0.37$ & $1.81 \pm 0.33$ \\
\hline & SH & $1.23 \pm 0.16$ & $1.20 \pm 0.24$ & $1.00 \pm 0.14^{*}$ & $1.13 \pm 0.29$ & $1.17 \pm 0.32^{*}$ & $1.56 \pm 0.48$ \\
\hline \multirow{2}{*}{ LDL-C (mmol/L) } & N & $0.51 \pm 0.16$ & $0.42 \pm 0.14$ & $0.33 \pm 0.13$ & $0.34 \pm 0.10$ & $0.37 \pm 0.08$ & $0.48 \pm 0.16$ \\
\hline & SH & $0.44 \pm 0.10$ & $0.40 \pm 0.10$ & $0.28 \pm 0.08$ & $0.30 \pm 0.11$ & $0.31 \pm 0.13$ & $0.39 \pm 0.17$ \\
\hline \multirow{2}{*}{ FGF23 (ng/L) } & N & $203 \pm 26$ & $196 \pm 31$ & $195 \pm 35$ & $183 \pm 33$ & $184 \pm 33$ & $172 \pm 24$ \\
\hline & SH & $175 \pm 20^{*}$ & $170 \pm 24^{*}$ & $177 \pm 34$ & $179 \pm 25$ & $169 \pm 19$ & $175 \pm 24$ \\
\hline \multirow{2}{*}{ PTH (ng/L) } & N & $39.4 \pm 3.93$ & $40.6 \pm 5.14$ & $40.4 \pm 6.11$ & $39.3 \pm 5.95$ & $38.2 \pm 6.50$ & $38.0 \pm 6.47$ \\
\hline & SH & $39.6 \pm 3.55$ & $38.0 \pm 5.76$ & $41.6 \pm 7.33$ & $40.6 \pm 7.43$ & $39.0 \pm 6.06$ & $38.8 \pm 5.67$ \\
\hline \multirow{2}{*}{$1,25(\mathrm{OH})_{2} \mathrm{D}_{3}(\mathrm{ng} / \mathrm{L})$} & $\mathbf{N}$ & $91.6 \pm 6.71$ & $98.5 \pm 14.1$ & $95.5 \pm 10.8$ & $93.8 \pm 13.8$ & $94.5 \pm 14.2$ & $88.2 \pm 10.8$ \\
\hline & SH & $89.1 \pm 10.5$ & $91.5 \pm 13.5$ & $88.2 \pm 11.9$ & $90.2 \pm 13.3$ & $89.8 \pm 10.5$ & $84.3 \pm 9.2$ \\
\hline \multirow{2}{*}{ CXT (nmol/L) } & $\mathbf{N}$ & $10.25 \pm 1.77$ & $10.8 \pm 2.73$ & $10.25 \pm 2.73$ & $11.16 \pm 2.77$ & $10.17 \pm 2.77$ & $9.93 \pm 3.34$ \\
\hline & SH & $7.73 \pm 1.29 * *$ & $8.08 \pm 2.17^{* *}$ & $8.16 \pm 2.07^{*}$ & $8.34 \pm 2.19 * *$ & $8.08 \pm 2.11^{*}$ & $7.08 \pm 1.21^{*}$ \\
\hline \multirow{2}{*}{ Milk yield (Kg) } & $\mathbf{N}$ & & & $9.13 \pm 2.50$ & $24.47 \pm 4.97$ & $32.21 \pm 8.36$ & $34.96 \pm 6.59$ \\
\hline & SH & & & $10.04 \pm 3.33$ & $28.79 \pm 4.98$ & $36.59 \pm 4.92$ & $38.70 \pm 4.52$ \\
\hline
\end{tabular}

Explanations: * significant differences between the subclinical hypocalcemia and normocalcemia groups, $\mathrm{P}<0.05 ; * *$ significant differences between the subclinical hypocalcemia and normocalcemia groups, $\mathrm{P}<0.01 ; \mathrm{N}-$ normocalcemia group ( $\mathrm{n}=64$ ); $\mathrm{SH}-$ subclinical hypocalcemia group $(\mathrm{n}=52)$

than they were in the normocalcemic cows 1 week prepartum. Lean et al. (8) also observe that the concentration of dietary $\mathrm{P}$ in dairy cows is closely related to the risk of developing milk fever. Similarly, Goff (2) suggests that a diet providing pregnant dairy cattle with more than $80 \mathrm{~g}$ of $\mathrm{P}$ per day may block the production of $1,25(\mathrm{OH})_{2} \mathrm{D}_{3}$. A low concentration of $1,25(\mathrm{OH})_{2} \mathrm{D}_{3}$ was detected from prepartum week 2 to postpartum day 7 in the subclinical hypocalcemia group, which was thought to be caused by high plasma $\mathrm{P}$ concentrations.
FGF23 release is markedly stimulated by $1,25(\mathrm{OH})_{2} \mathrm{D}_{3}$ and plays an important role in excretion of $\mathrm{P}$ by the kidneys (7). It seems that the increased plasma P concentration in the subclinically hypocalcemic cows was due to the lower plasma concentration of FGF23. Thus, high plasma $\mathrm{P}$ concentrations may be a major cause of the low bone turnover and $1,25(\mathrm{OH})_{2} \mathrm{D}_{3}$-mediated intestinal absorption of $\mathrm{Ca}$.

A significantly increased AST concentration was detected in plasma samples from the subclini- 
cally hypocalcemic dairy cows on postpartum day 3 . According to Seifi et al. (15), the increased activity of AST might be attributed to a higher incidence of milk fever, and a variety of tissues have high AST activity in a state of hypocalcemia (e.g., striated muscle and the liver). However, in the subclinically hypocalcemic cows, AST activity was dramatically higher on postpartum day 1 than it was 1 week prepartum, while increased AST activity was detected on postpartum day 3 . Thus, high AST activity on postpartum day 3 was suggested to attribute to hypocalcemia (15). Interestingly, plasma TC concentrations were low during the transition period, especially in the subclinically hypocalcemic dairy cows, and postpartum HDL-C in those cows was significantly lower than it was in the normocalcemic group. Yamamoto et al. (18) report that apolipoprotein C (apoC)-III concentrations were distinctly decreased in cows with milk fever. Transcription of the apoC-III gene is regulated by mitogen-activated protein kinase. Phosphorylation by this kinase of retinoid $\mathrm{X}$ receptor $\alpha$, a member of the nuclear receptor family, results in the inhibition of $1,25(\mathrm{OH})_{2} \mathrm{D}_{3}$-dependent signal transduction (16) in the regulation of $\mathrm{Ca}$ metabolism. Together, these findings suggest that, since apoC-III and apoC-related HDLs are involved in the development of milk fever, the monitoring of apoC-III concentrations during the peripartum period may be helpful in identifying cows susceptible to fatty liver-associated diseases, such as milk fever.

Prediction model of subclinical hypocalcemia in dairy cows. To predict subclinical hypocalcemia in the prepartum period, the data for each plasma biochemical analyte 1 and 2 weeks prepartum were pooled. As shown by the results of the univariate analysis of the pooled data presented in Table 3, plasma FGF23, CTX, $\mathrm{P}, \mathrm{Ca}, \mathrm{NEFA}, 1,25(\mathrm{OH})_{2} \mathrm{D}_{3}$, HDL-C, and $\mathrm{Mg}$ were significantly predictive of subclinical hypocalcemia (Plasma biochemical analytes with $\mathrm{P}>0.25$ are not shown). Then, multiple logistic regression analysis was performed for the subclinical hypocalcemia and normocalcemia groups. As show in Table 3, the overall history model had a ROC area of 0.91 . Further exclusions and other combinations of predictors decreased the ROC area. The combination of FGF23, CXT, and $\mathrm{Ca}$ was selected as the final model for prediction of subclinical hypocalcemia in the prepartum period. The model was then transformed to the following easily applicable scoring rule:

$38.8-0.052 * \mathrm{FGF} 23-0.492 * \mathrm{CTX}-10.645 * \mathrm{Ca}$, where a score of $>0$ was considered as an indication of increased risk of subclinical hypocalcemia after calving. The prediction model has an accuracy of $79.3 \%$, sensitivity of $76.9 \%$, and specificity of $81.3 \%$.

\section{References}

1. Chamberlin W. G., Middleton J. R., Spain J. N., Johnson G. C., Ellersieck M. R., Pithua P.: Subclinical hypocalcemia, plasma biochemical parameters, lipid metabolism, postpartum disease, and fertility in postparturient dairy cows. J. Dairy Sci. 2013, 96, 7001-7013.

2. Goff J. P.: Macromineral disorders of the transition cow. Vet. Clin. North. Am. Food Anim. Pract. 2004, 20, 471-494.

3. Goff J. P.: The monitoring, prevention, and treatment of milk fever and subclinical hypocalcemia in dairy cows. Vet. J. 2008, 176, 50-57.

4. Jawor P. E., Huzzey J. M., LeBlanc S. J., von Keyserlingk M. A.: Associations of subclinical hypocalcemia at calving with milk yield, and feeding, drinking, and standing behaviors around parturition in Holstein cows. J. Dairy Sci. 2012, 95, 1240-1248.

5.Kim D., Yamagishi N., Ueki A., Miura M., Saito F., Sato S., Furuhama K.: Changes in plasma bone metabolic markers in periparturient dairy cows. J. Vet. Med. Sci. 2010, 72, 773-776.

6. Kimura K., Reinhardt T. A., Goff J. P.: Parturition and hypocalcemia blunts calcium signals in immune cells of dairy cattle. J. Dairy Sci. 2006, 89, 2588-2595 .

7. Lang F., Foller M.: Enigmatic Cassandra: renal FGF23 formation in polycystic kidney disease. Kidney Int. 2014, 85, 1260-1262.

8. Lean I. J., DeGaris P. J., McNeil D. M., Block E.: Hypocalcemia in dairy cows: meta-analysis and dietary cation anion difference theory revisited. J. Dairy Sci. 2006, 89, 669-684.

9. Martinez N., Risco C. A., Lima F. S., Bisinotto R. S., Greco L. F., Ribeiro E. S., Maunsell F., Galvao K., Santos J. E.: Evaluation of peripartal calcium status, energetic profile, and neutrophil function in dairy cows at low or high risk of developing uterine disease. J. Dairy Sci. 2012, 95, 7158-7172.

10. Martinez N., Sinedino L. D., Bisinotto R. S., Ribeiro E. S., Gomes G. C., Lima F. S., Greco L. F., Risco C. A., Galvao K. N., Taylor-Rodriguez D.: Effect of induced subclinical hypocalcemia on physiological responses and neutrophil function in dairy cows. J. Dairy Sci. 2014, 97, 874-887.

11. Mulligan F. J., O'Grady L., Rice D. A., Doherty M. L.: A herd health approach to dairy cow nutrition and production diseases of the transition cow. Anim. Reprod. Sci. 2006, 96, 331-353.

12. Nedic S., Palamarevic M., Arsic S., Jovanovic L., Prodanovic R., Kirovski D., Vujanac I.: Parathyroid hormone response in treatment of subclinical hypocalcemia in postpartum dairy cows. Res. Vet. Sci. 2020, 132, 351-356. 
13. Perwad F., Zhang M. Y., Tenenhouse H. S., Portale A. A.: Fibroblast growth factor 23 impairs phosphorus and vitamin D metabolism in vivo and suppresses 25-hydroxyvitamin D-1alpha-hydroxylase expression in vitro. Am. J. Physiol. Renal. Physiol. 2007, 293, F1577-1583.

14. Reinhardt T. A., Lippolis J. D., McCluskey B. J., Goff J. P., Horst R. L.: Prevalence of subclinical hypocalcemia in dairy herds. Vet. J. 2011, 188, 122-124.

15. Seifi H. A., Mohri M., Farzaneh N., Nemati H., Nejhad S. V.: Effects of anionic salts supplementation on blood $\mathrm{pH}$ and mineral status, energy metabolism, reproduction and production in transition dairy cows. Res. Vet. Sci. 2010, 89, 72-77.

16. Solomon C., White J. H., Kremer R.: Mitogen-activated protein kinase inhibits 1,25-dihydroxyvitamin D3-dependent signal transduction by phosphorylating human retinoid X receptor alpha. J. Clin. Invest. 1999, 103, 1729-1735.

17. Yamada S., Inaba M., Kurajoh M., Shidara K., Imanishi Y., Ishimura E., Nishizawa Y.: Utility of serum tartrate-resistant acid phosphatase (TRACP5b) as a bone resorption marker in patients with chronic kidney disease: independence from renal dysfunction. Clin. Endocrinol. (Oxf.) 2008, 69, 189-196.

18. Yamamoto M., Nakagawa-Ueta H., Katoh N., Oikawa S.: Decreased concentration of serum apolipoprotein C-III in cows with fatty liver, ketosis, left displacement of the abomasum, milk fever and retained placenta. J. Vet. Med. Sci. 2001, 63, 227-231.

19. Yang W., Zhang B., Xu C., Zhang H., Xia C.: Effects of Ketosis in Dairy Cows on Blood Biochemical Parameters, Milk Yield and Composition, and Digestive Capacity. J. Vet. Res. 2019, 63, 555-560.

20. Zhang B., Guo H., Yang W., Li M., Zou Y., Loor J. J., Xia C., Xu C.: Effects of ORAI calcium release-activated calcium modulator 1 (ORAI1) on neutrophil activity in dairy cows with subclinical hypocalcemia. J. Anim. Sci. 2019, 97, 3326-3336.

Corresponding author: Wei Yang, No. $2^{\text {nd }}$, Xinyang Road, 163319 DaQing, China; e-mail: yangwei416@126.com 